\title{
Squamous odontogenic tumor of the maxilla: Report of a case
}

\author{
Kaoru Kusama ${ }^{\S, \ddagger}$, Ayako Kawashima ${ }^{\S}$, Haruki Nagai ${ }^{\S}$, Mitsuaki Tajima ${ }^{\S}$, \\ Hoaki Tsuchiya ${ }^{\S}$, Haruhiko Yamaguchi ${ }^{\dagger}$, Makoto Furuya ${ }^{\dagger}$, \\ Masaaki Terakado ${ }^{\dagger}$, Hiroshi Sato ${ }^{\dagger}$ and Itaru Moro ${ }^{\S, \ddagger}$
}

Departments of ${ }^{\S}$ Pathology and ${ }^{\dagger}$ Oral and Maxillofacial Surgery, Nihon University School of Dentistry
Laboratory of Tissue and Cell Culture ${ }^{\ddagger}$, Dental Research Center, Nihon University School of Dentistry, Tokyo 101-8310

(Received 11 March and accepted 17 June 1998)

\begin{abstract}
A case of squamous odontogenic tumor (SOT) of the maxilla related to an embedded tooth in a 42-year-old Japanese woman is described. The patient felt a slight pain of her left maxilla 2 months before visiting our dental hospital. Histologically, the tumor consisted of a proliferation of round and elongated epithelial islands of well-differentiated squamous epithelium separated by a fibrous stroma. The epithelial nests varied in size, and were composed of cuboidal or squamous cells of basal layer and matured intermediate cells with prominent intercellular bridges. Although no calcified materials were found, microcystic degeneration was occasionally observed in the epithelial islands. These findings indicated that this tumor is a SOT of the maxilla. (J. Oral Sci. 40, 119-122, 1998)
\end{abstract}

Key words: squamous odontogenic tumor; WHO classification; oral cavity.

\section{Introduction}

A squamous odontogenic tumor (SOT), first described by Pullon et al. (1) in 1975, is a rare lesion thought to arise from the remnants of the dental lamina, rests of Malassez or overlying epithelium. This type of tumor, classified as a benign epithelial odontogenic tumor by the WHO (2), is a rare, sometimes multifocal, potentially aggressive lesion, consisting of islands of stratified squamous epithelium that usually contain microcysts and lamellar calcification in a dense fibrous connective tissue. In this study, we describe a case of SOT related to an embedded tooth in the maxilla.

\section{Case Report}

A 42-year-old Japanese woman visited our dental hospital in September 1996 complaining of a slightly painful swelling of the maxilla. The patient had felt the pain for about 2 months. Intraoral examination revealed a relatively hard swelling of the buccal gingiva in the left maxillary premolar region. The second premolar was not found and rotation of the first premolar was observed. X-

Correspondence to Dr. Kaoru Kusama, Department of Pathology, Nihon University School of Dentistry, 1-8-13, Kanda-Surugadai, Chiyoda-ku, Tokyo 101-8310, Japan ray examination revealed a well-defined unilocular and radiolucent lesion with an embedded tooth in the maxillary left premolar area (Fig. 1). There was no swelling of the lymph nodes in the submandibular or cervical regions. The results of her physical examination were normal and her medical history was noncontributory. The clinical diagnosis was a dentigerous cyst. Surgery was performed under local anesthesia. The lesion was a well-demarcated tumor related to the crown of the embedded tooth and there was no evidence of local infiltration into the adjacent bony tissue. The tumor was almost solid on the cut surface, while small cystic changes were found. No relationship between the small cystic changes and the embedded tooth was observed.

Microscopically, the lesion was composed of numerous islands of well-differentiated squamous epithelium in a fibrous tissue (Fig. 2). The epithelial islands occasionally had microcystic degeneration, though no calcified materials were found. The epithelial nests had a peripheral layer of cuboidal or squamous cells, but columnar cells which are typically seen in ameloblastoma were not observed. The intermediate cells in the epithelial island were characterized by the presence of intercellular bridges (Fig. 3). Formations of larger cystic spaces were found and papillary proliferation of epithelial cells associated with a fibrous stroma into the space was also observed (Fig. 4). Although mucoid material was found in parts of the epithelial nests, neither calcified materials nor keratin pearl were observed. The connective tissue stroma contained mature collagen fibers, while mucinous degeneration was found in some regions. Numerous small or elongated nests resembling rests of Malassez or remnants of the dental lamina were found in the peripheral area of the tumor (Fig. 5).

Although the initial pathological diagnosis was a benign odontogenic epithelial tumor, a final diagnosis of squamous odontogenic tumor was established. There was no recurrence on re-examination one year and eight months after the operation.

\section{Discussion}

The SOT is a rare, benign odontogenic epithelial tumor originally described by Pullon et al. (1) and 36 reported cases of the tumor were reviewed by Philipsen and 
Reichart (3) in 1996.

In the recent WHO classification of odontogenic tumors (2), the SOT is defined as: A benign but locally infiltrative neoplasm consisting of islands of welldifferentiated squamous epithelium in a fibrous stroma. The epithelial islands occasionally show foci of central cystic degeneration.

In the present case, the epithelial islands varied in size and shape, and were composed of well-differentiated squamous epithlium with a peripheral layer of inactiveappearing flattened or cuboidal cells in a fibrous connective tissue. Although microcystic degeneration was often found in the islands, larger cystic formations and papillary proliferation of the epithelial component with a fibrous stroma into the cystic space were observed. Schwartz-Arad et al. (4) reported a case of SOT showing papillary hyperplasia or papillomatous proliferation. The

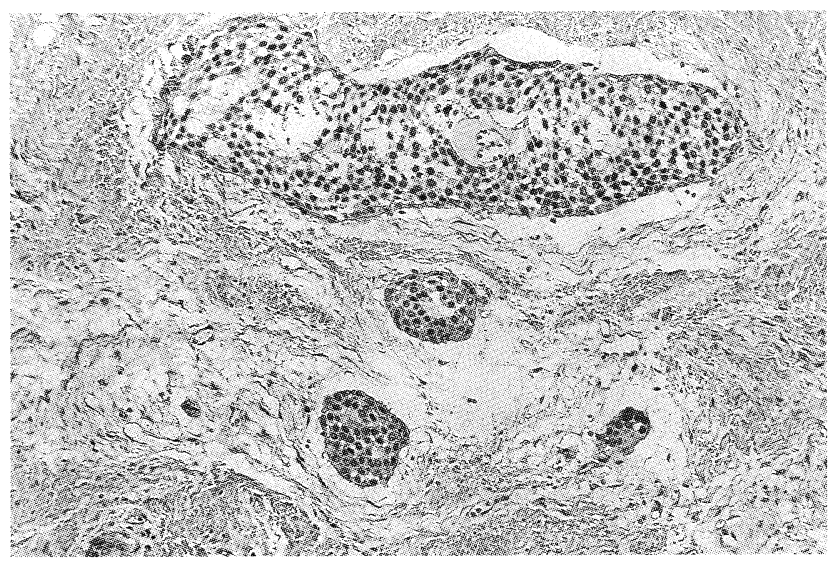

Fig. 2 Neoplastic islands of squamous epithelium with microcyst formation. (Hematoxylin-eosin stain)

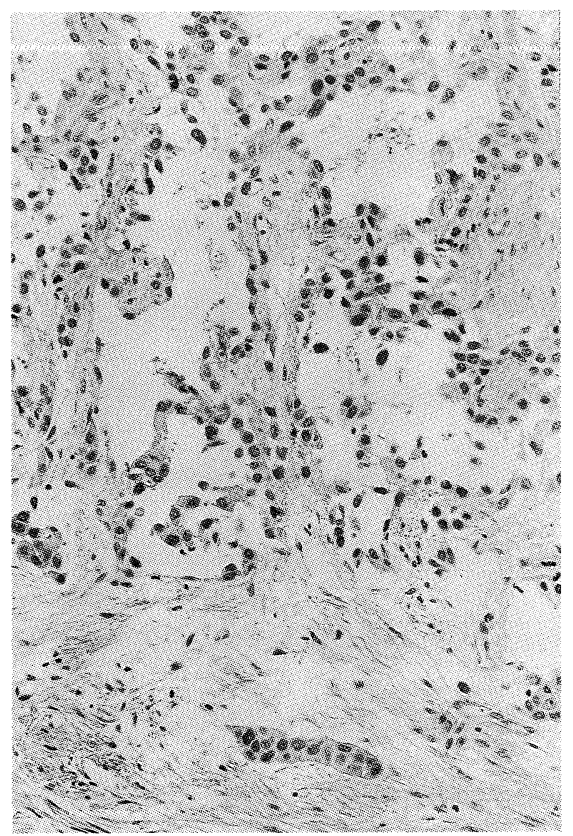

Fig. 4 Larger cystic formation and papillary proliferation of epithelial cells associated with a fibrous stroma. (Hematoxylin-eosin stain)

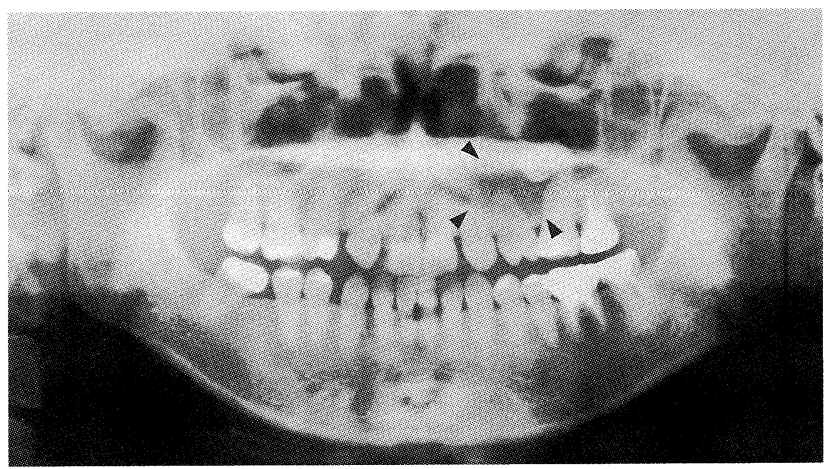

Fig. 1 Radiograph showing a well-defined unilocular lesion with an embedded tooth in the left maxillary premolar area. (arrow heads)

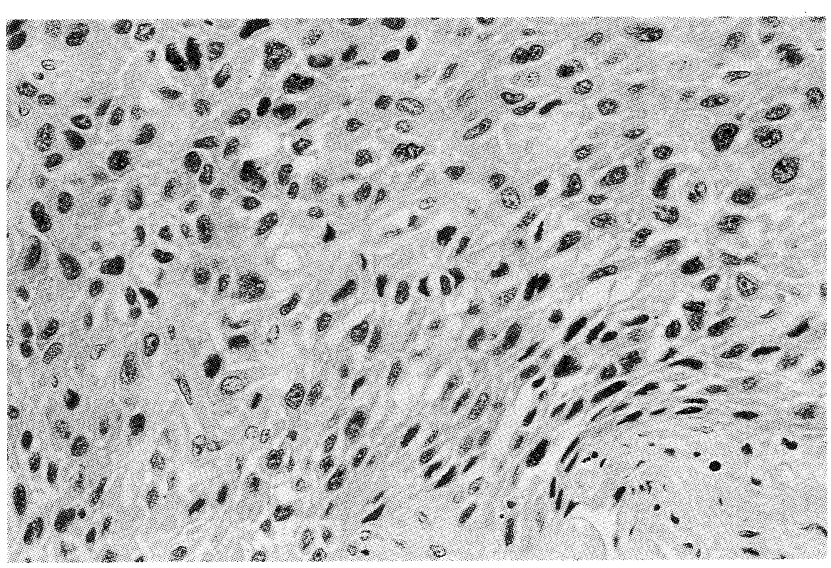

Fig. 3 Tumor cells showing the characteristics of welldifferentiated squamous epithelium. (Hematoxylineosin stain)

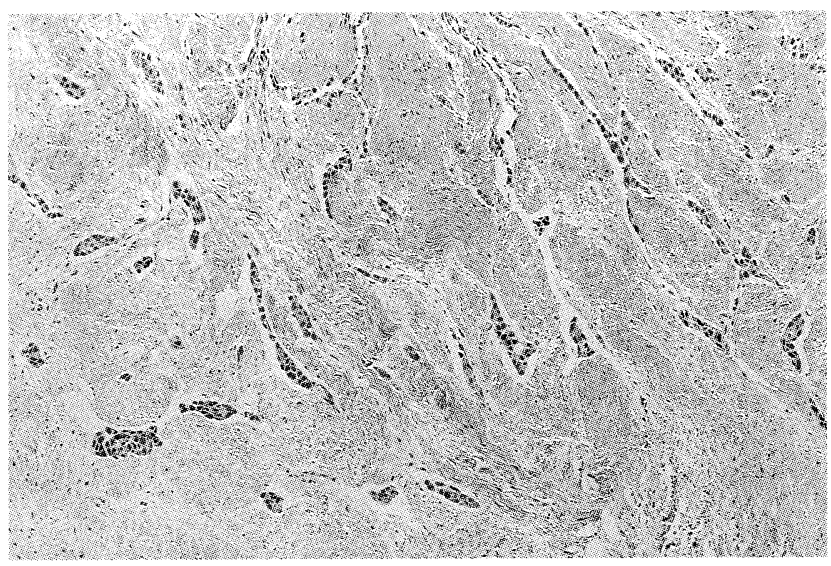

Fig. 5 Numerous small or elongated nests resembling rests of Malassez or remnants of the dental lamina in the peripheral area of the tumor. (Hematoxylin-eosin stain) 
initial pathological diagnosis of their case was made as moderately differentiated squamous cell carcinoma. There have been several reported cases of SOT which the initial pathological diagnosis, such as acanthomatous ameloblastoma (1,5-7), ameloblastic fibroma (1) and squamous cell carcinoma $(4,8)$, was different from the final diagnosis.

In making a diagnosis of SOT, a distinction needs to be made between this lesion and ameloblastoma. The epithelial islands in the SOT composed of welldifferentiated squamous epithelium have a peripheral layer of flattened or cuboidal cells, and lack columnar and stellete reticulum-like cells typically seen in the ameloblastoma.

Although mucoid material was found in portions of the epithelial nests, no calcified materials were seen in the nest or stroma. Kristensen et al. (6) reported the presence of mucoid material in some of the microcystic formation, which was often mixed with keratotic material. The cases of SOT in which no calcification was found in the both epithelial nests and stroma have been reported (6,9-11). Calcified materials in the SOT showed a lamellated structure or deposition. These morphological features suggest that the calcification in the SOT may be dystrophic materials and not be produced by tumor cells. Swan and McDaniel (11) reported a case considered to be early SOT in which no calcified materials and keratin pearls were observed in the epithelial nests. There have also been many cases of SOT $(1,4,6,8,12-17)$ in which keratin pearls and eosinophilic crystalloids were found in the center of epithelial nests. These disparate findings may reflect the degree of differentiation of tumor nests.

The origin of the SOT is thought to be from rests of Malassez or remnants of the dental lamina (2). However, there have been several reports $(4,6,12,17,18)$ of cases related to overlying oral epithelium. Furthermore, cases of SOT-like proliferation associated with odontogenic cysts have been reported $(5,14,19-23)$. In the present case, the tumor was related to an embedded tooth and numerous small or elongated nests resembling rests of Malassez or remnants of the dental lamina were found in the peripheral area of the tumor. Thus, the SOT may arise from various odontogenic epithelial elements.

\section{References}

1. Pullon, P.A., Shafer, W.G., Elzay, R.P., Kerr, D.A. and Corio, R.L. (1975) Squamous odontogenic tumor. Report of six cases of a previously undescribed lesion. Oral Surg. Oral Med. Oral Pathol. 40, 616-630

2. Kramer, I.R.H., Pindborg, J.J. and Shear, M. (1992) Histological Typing of Odontogenic Tumours. 2nd ed., Springer-Verlag, Berlin, 14

3. Philipsen, H.P. and Reichart, P.A. (1996) Squamous odontogenic tumor (SOT): a benign neoplasm of the periodontium. A review of 36 reported cases. J. Clin. Periodontol. 23, 922-926

4. Schwartz-Arad, D., Lustmann, J. and Ulmansky, M. (1990) Squamous odontogenic tumor. Review of the literature and case report. Int. J. Oral Maxillofac. Surg. 19, 327-330
5. Doyle, J.L., Grodjesk, J.E., Dolinsky, H.B. and Rafel, S.S. (1977) Squamous odontogenic tumor: report of three cases. J. Oral Surg. 35, 994-996

6. Kristensen, S., Andersen, J. and Jacobsen, P. (1985) Squamous odontogenic tumour. Review of the literature and a new case. J. Laryngol. Otol. 99, 919. 924

7. Mills, W.P., Davila, M.A., Beuttenmuller, E.A. and Koudelka, B.M. (1986) Squamous odontogenic tumor. Report of a case with lesions in three quadrants. Oral Surg. Oral Med. Oral Pathol. 61, 557 563

8. Norris, L.H., Baghaei-Rad, M., Maloney, P.L., Simpson, G. and Guinta, J. (1984) Bilateral maxillary squamous odontogenic tumors and the malignant transformation of a mandibular radiolucent lesion. J. Oral Maxillofac. Surg. 42, 827-834

9. Hietanen, J., Lukinmaa, P.L., Ahonen, P., Krees, R. and Calonius, P.E.B. (1985) Peripheral squamous odontogenic tumor. Br. J. Oral Maxillofac. Surg. 23, 362-365

10. Yaacob, H.B. (1990) Squamous odontogenic tumor. J. Nihon Univ. Sch. Dent. 32, 187-191

11. Swan, R.H. and McDaniel, R.K. (1983) Squamous odontogenic proliferation with probable origin from the rests of Malassez (early squamous odontogenic tumor?). J. Periodontol. 54, 493-496

12. McNeill, J., Price, H.M. and Stoker, N.G. (1980) Squamous odontogenic tumor: report of case with long-term history. J. Oral Surg. 38, 466-471

13. Carr, R.F., Carlton, D.M. Jr. and Marks, R.B. (1981) Squamous odontogenic tumor: report of case. J. Oral Surg. 39, 297-298

14. Goldblatt, L.I., Brannon, R.B. and Ellis, G.L. (1982) Squamous odontogenic tumor. Report of five cases and review of the literature. Oral Surg. Oral Med. Oral Pathol. 54, 187-196

15. Cataldo, E., Less, W.C. and Giunta, J.L. (1983) Squamous odontogenic tumor. A lesion of the periodontium. J. Periodontol. 54, 731-735

16. Tatemoto, Y., Okada, Y. and Mori, M. (1989) Squamous odontogenic tumor: immunohistochemical identification of keratins. Oral Surg. Oral Med. Oral Pathol. 67, 63-67

17. Baden, E., Doyle, J., Mesa, M., Fabie, M., Lederman, D. and Eichen, M. (1993) Squamous odontogenic tumor: Report of three cases including the first extraosseous case. Oral Surg. Oral Med. Oral Pathol. 75, 733-738

18. Leider, A.S., Jonker, L.A. and Cook, H.E. (1989) Multicentric familial squamous odontogenic tumor. Oral Surg. Oral Med. Oral Pathol. 68, 175-181

19. Hopper, T.L., Sadeghi, E.M. and Pricco, D.F. (1980) Squamous odontogenic tumor. Report of a case with multiple lesions. Oral Surg. Oral Med. Oral Pathol. 50, 404-410

20. Leventon, G.S., Happonen, R.P. and Newland, J.R. (1981) Squamous odontogenic tumor. Report of two cases and review of the literature. Am. J. Surg. Pathol. 5, 671-677 
21. Anneroth, G. and Hansen, L.S. (1982) Variations in keratinizing odontogenic cysts and tumors. Oral Surg. Oral Med. Oral Pathol. 54, 530-546

22. Wright, J.M. Jr. (1979) Squamous odontogenic tumorlike proliferations in odontogenic cysts. Oral Surg.
Oral Med. Oral Pathol. 47, 354-358

23. Simon, J.H. and Jensen, J.L. (1985) Squamous odontogenic tumor-like proliferations in periapical cysts. J. Endodont. 11, 446-448 